\title{
ONTOGENY OF OPIOID AND RELATED PEPTIDES IN THE RAT CNS AND PITUITARY: AN IMMUNOCYTOCHEMICAL STUDY
}

Henry Khachaturian, Norman E. Alessi, Nabil Munfakh, Stanley J. Watson

\author{
Mental Health Research Institute \\ University of Michigan \\ Ann Arbor, Michigan 48109
}

(Received in final form June 26, 1983)

\begin{abstract}
Summary
The development of proopiomelanocortin (POMC) derived peptides was compared to that of leucine-enkephalin ([Leu]ENK) and dynorphin A (DYN-A) immunoreactivity (i.r.) in the rat CNS and pituitary gland. POMC i.r. appeared first in hypothalamic neurons on embryonic day $\mathrm{E12}$, in pituitary anterior lobe (AL) cells on E15, in pituitary intermediate lobe (II) cells on E16, and in perikarya of the nucleus tractus solitarius on E17. In the fetal stages (E19-22), all POMC systems appeared adult-like; however, peak i.r. occurred between postnatal days P21-28. The development of alpha-MSH (a-MSH) i.r. was dissimilar to that of other POMC peptides including beta-endarphin (B-End). In contrast, both [Leu]ENK and DYN-A i.r. appeared in later embryonic stages (E16-17), and their maturation lagged behind that of POMC peptides. Peak i.r. for these latter peptides also occurred between P21-28.
\end{abstract}

The developmental patterns of the opioid and related peptides, or their role in physiological processes during ontogeny have, at best, received scant experimental attention. The ontogeny of POMC related peptide i.r. in the embryonic pituitary has been studied by a few investigators (cf. 1). $B-E N D$, ACTH and a-MSH cells appear to arise earlier in gestation in the AL (E15-16) than in the IL (E17) of the rat pituitary $(2,3)$. Furthermore, in the brain, the B-END-containing neurons exhibit i.r. on E12-13, and demonstrate adult-like patterns by late gestation ( 3,4$)$. on the other hand, [Leu]ENK i.r. appears less advanced at these early stages of development when compared to B-END, as measured by radioimmunoassay (4). [Leu]-ENK-containing processes and cells have been detected at E15-16 and E18, respectively $(5,6)$. Radioimmunoassayable levels of B-END and [Leu]ENK increase rapidly, yet independently, during postnatal periods to reach adult-like distribution patterns by P25 (4).

In the present study, we report on the comparative pre- and postnatal ontogeny of the opioid and related peptides in the rat CNS and pituitary gland, including the heretofore undescribed immunocytochemical ontogeny of DYN-A i.r. in the brain and pituitary, as well as the little-known POMCcontaining neurons in the nucleus tractus solitarius $(7)$.

\section{Me thods}

Sprague-Dawley female rats used in this study were either bred in our $0024-3205 / 83 \$ 3.00+.00$

Copyright (c) 1983 Pergamon Press Ltd. 
laboratory or obtained timed-pregnant from Charles-River breeding labs. Embryos were dated according to their crown-rump length (8). Postnatal rats were treated with colchicine (0.5 - 1.0 microgram/g body wt.) 24-48 hrs. prior to sacrifice. The animals were either decapitated and the head fixed in $4 \%$ formaldehyde (up to E14), or were perfused through the heart with the same fixative, and postfixed. Following fixation, all tissues were immersed in 15\% sucrose overnight, frozen in liquid nitrogen and sectioned at 20 microns. Frozen sections were processed for PAP immunocytochemistry as described before ( 9 ).

\section{Results}

The POMC peptides (with the exception of a-MSH) appeared first on E12 in small i.r. perikarya in the medial basal hypothalamus (arcuate nucleus, Fig. 1A). These neurons matured rapidly, since scattered immunoreactive (i.r.) hypothalamic fibers were visible by E15. By E16, i.r. POMC fibers could be seen in the periaqueductal gray, brainstem and spinal cord. At E17, small perikarya $i . r$. to $16 \mathrm{~K}$ (N-terminal fragment of POMC) also appeared in the nucleus tractus solitarius (Fig. 1E, from E21), and by P1, these perikarya also exhibited i.r. to ACTH and B-END, but not to a-MSH. By late gestation, the distribution of POMC perikarya (Fig. 1B) and fibers in the brain resembled adult patterns; however, peak i.r. occurred at P21-28. Conversely, a-MSH i.r. matured relatively slowly in the arcuate nucleus (starting at E16), and was always less pronounced than 16K, ACTH and B-END. Furthermore, the so-called alpha-2 (a-MSH i.r.) neurons of the posterolateral hypothalamus were only visible postnatally (starting at P1, Fig. 1F), and only after colchicine pretreatment. Another significant observation was that the POMC perikarya in the nucleus tractus solitarius exhibited only faint a-MSH i.r. at the later postnatal stages studied (P21-28), and only after colchicine pretreatment.

In the pituitary $A L$, a few $16 \mathrm{~K} / \mathrm{ACTH} / \mathrm{B}-\mathrm{END}$ cells appeared first on E15 (Fig. 1C), and in the IL on E16 (Fig. 1D, from E17). Conversely, a-MSH i.r. was detected in the AL on E16 and in the IL on E17. By E19, the pituitary appeared adult-like with the exception of a-MSH i.r. in the AL corticotrophs. Postnatally, a-MSH i.r. in the AL corticotrophs began to decline in intensity at P14, and by P28 a-MSH i.r. in the corticotrophs was faint.

[Leu]ENK and DYN-A i.r. appeared later in embryonic development when compared to POMC development in the brain. At E16, both [Leu]ENK and DYN-A i.r. fibers could be seen in the ventral brainstem and spinal cord. By E17, diffuse DYN-A i.r. could be detected in the posterior pituitary (Fig. 2A). At E18-19, faintly i.r. [Leu]ENK perikarya were detected in the brainstem, and DYN-A i.r. magnocellular perikarya could be seen in the supraoptic nucleus. Starting at $P 1$, and with colchicine pretreatment, most [Leu]ENK and DYN-A (Fig. 2B) i.r. perikarya described in the adult brain (cf. 9-11) were also demonstrable. From $P 7$ to P21, both [Leu]ENK and DYN-A i.r. perikarya and fiber density increased to reach a peak at P21-28.

\section{Discussion}

Our results agree with those of other investigators on the prenatal development of POMC and enkephalin neuronal systems in the rat brain $(3,5,6)$, with the possible exception that we were able to visualize only faint i.r. [Leu]ENK perikarya during late gestational ages $(5,6)$. These perikarya were demonstrable starting at P1, with colchicine pretreatment. The POMC system in the arcuate nucleus develops earlier than that in the nucleus tractus solitarius, as well as both [Leu]ENK and DYN-A systems. This is consistent with the fact that arcuate POMC neurons form long-tract 


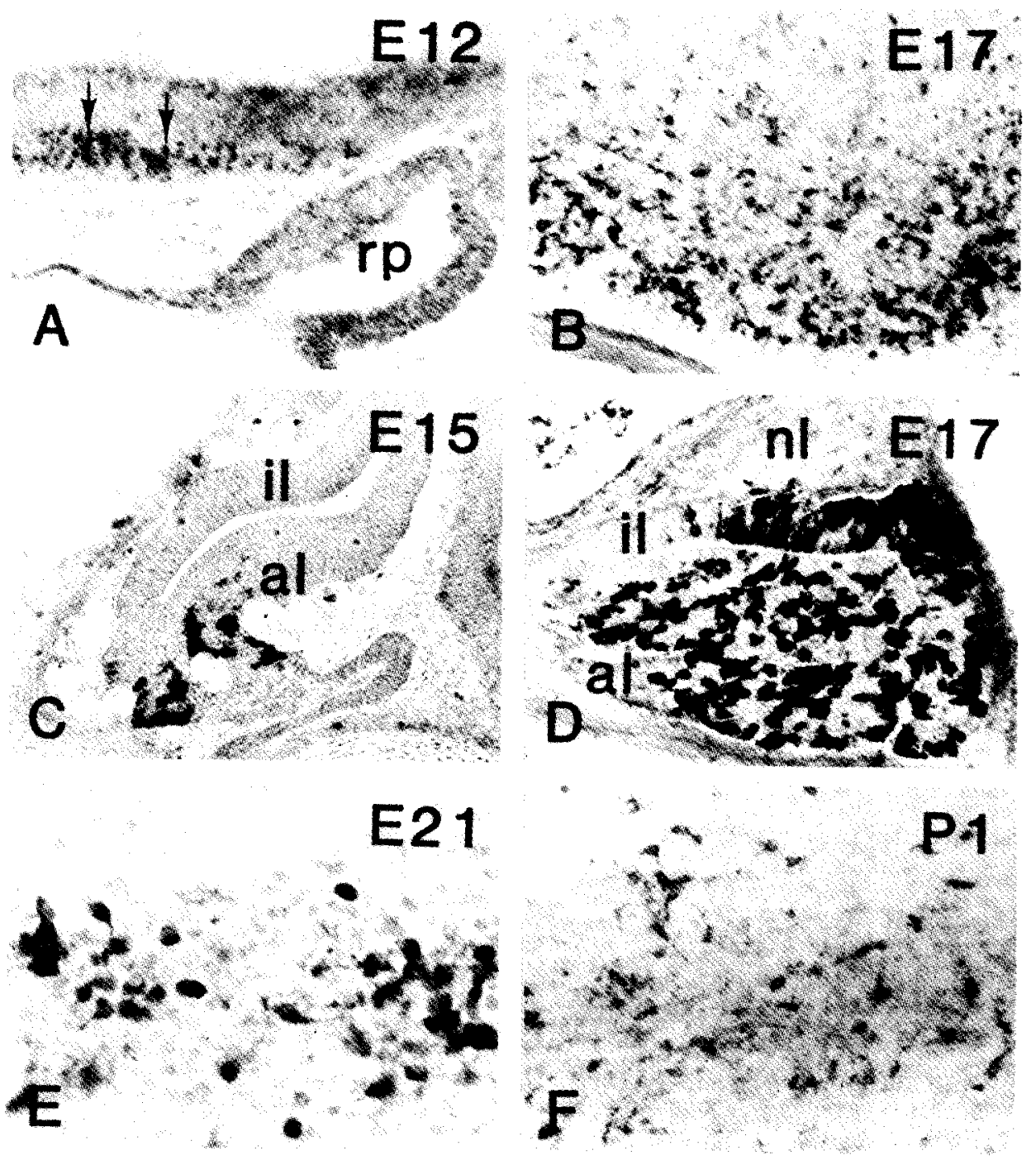

Fig. 1. A: Arcuate neurons (arrows) at E12 (ACTH). B: Arcuate neurons at E17 (16K). C.: Anterior lobe cells at E15 (ACTH). D: Anterior and intermediate lobe cells at E17 (16K). E: Nucleus tractus solitarius neurons at E21 (16K). F: alpha-2 neurons at P1 (colchicine pretreated) (a-MSH). $r p=$ rathke's pouch, al = anterior lobe, il = intermediate lobe, $\mathrm{nl}=$ neural lobe. Magnifications: $\mathrm{A}-\mathrm{D}, \mathrm{F}=\mathrm{X} 175 . \mathrm{E}=\mathrm{X} 437$.

projectional systems, while the POMC system in the nucleus tractus solitarius as well as certain [Leu]ENK and DYN-A neurons form local circuits. It is currently not clear whether some [Leu]ENK neurons arise earlier than others, however, we do know that magnocellular neurons (which contain DYN-A) are among the early arising hypothalamic neurons. Interestingly, the POMC perikarya of nucleus tractus solitarius were relatively easily demonstrable during late gestation (e.g., E21). In contrast, the adult nucleus tractus 
solitarius perikarya exhibit only faint $i . r$. to POMC peptides, and only after colchicine pretreatment. It is also of interest to note that most of the DYN-A i.r. neurons that we have reported in the adult brain (11), are also visible at P1 with colchicine pretreatment, but only magnocellular hypothalamic and posterior pituitary DYN-A i.r. could be detected prenatally.
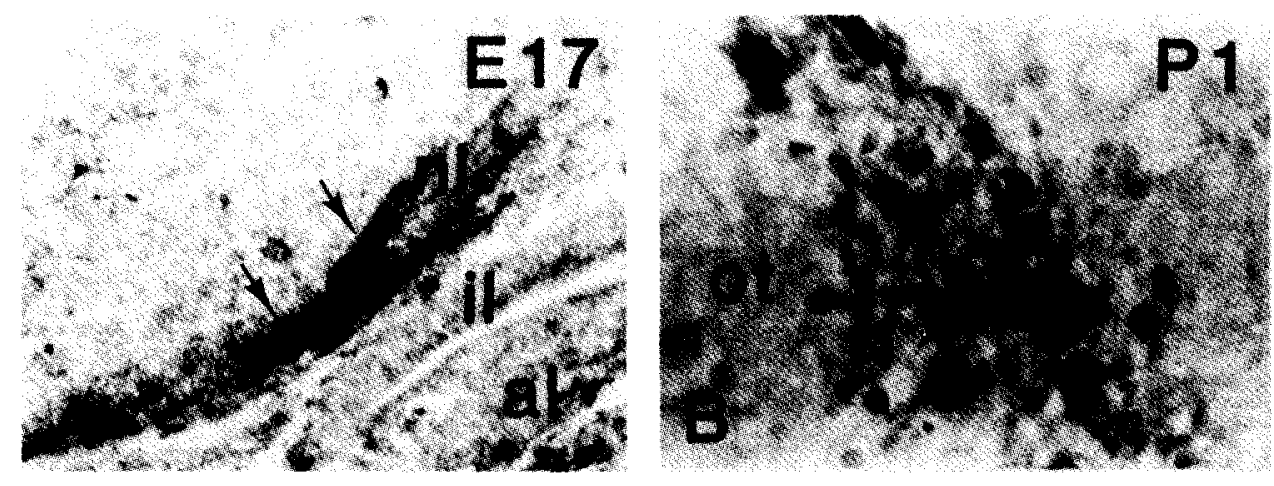

Fig. 2. Dynorphin A immunoreactivity in the neural lobe (arrows) at E17 (A) and in supraoptic magnocellular neurons at $\mathrm{P1}$ (B). al = anterior lobe, $i l=$ intermediate lobe, $n l=$ neural lobe, ot = optic tract. Magnifications: $A=X 175, B=X 437$.

\section{Acknowledgements}

This work was supported by NIMH training grant MH15794 to HK and NIMH Grant MH36851 to SJW.

\section{References}

1. J.P. DUPOUY, Int. Rev. Cytol. 68 197-249 (1980)

2. A. CHATELAIN, J.P. DUPOUY and M.P. DUBOIS, Cell Tiss. Res. 196 409-427 (1979).

3. D.G. SCHWARTZBERG and P.K. NAKANE, Endocrinology 110 855-864 (1982).

4. A. BAYON, W.J. SHOWMAKER, F.E. BLOOM, A. MAUSS and R. GUILLEMIN, Brain Res. 179 93-101 (1979).

5. M.R. PALMER, R.J. MILLER, L. OLSON and A. SEIGER, Medical Biol. 60 $61-88(1982)$.

6. V.M. PICKEL, K.K. SUMAL and R.J. MILLER, J. Comp.Neurol. 21 411-422 (1982).

7. D.G. SCHWARTZBERG and P.K. NAKANE, Soc. Neurosci. Abstr. 7224 (1981).

8. P.L. ALTMAN and D.S. DITTMER, Biology Data Book. Fed. Amer. Soc. Exp. Biol. (1984).

9. H. KHACHATURIAN, M.E. LEWIS, V. HOLLT and S.J. WATSON, J. Neurosci. 3 844-855 (1983).

10. H. KHACHATURIAN, M.E. LEWIS and S.J. WATSON, J. Comp. Neurol. in press.

11. H. KHACHATURIAN, S.J. WATSON, M.E. LEWIS, H. AKIL, D. COY and A. GOLDSTEIN, Peptides 3 941-954 (1982). 